\title{
Living within a Fair Share Ecological Footprint
}

\author{
edited by Robert Vale and Brenda Vale \\ New York: Earthscan/Routledge 2013 \\ ISBN: 978-0-415-5073-3 \\ Paperback, \$53.95, 344 pp.
}

\section{Reviewed by Debra J. Davidson \\ Department of Resource Economics and Environmental Sociology, University of Alberta}

The disconnect between society's consumption of natural resources and ecosystem services and the ability of our ecological and environmental systems to replenish themselves continues to grow, despite nearly 50 years of concerted attention inside and outside of academia. Debates continue as to whether closing this gap can be achieved through technology, behavioural change, and/or institutional change. The contributors to Robert and Brenda Vale's Living within a Fair Share Ecological Footprint join the growing chorus of technological skeptics, pointing to the fact that significant technological efficiency gains in recent decades have done little to stem our consumption of the earth's services. While nods to the need for institutional change are made throughout the volume, by and large these scholars focus on behavioural change, with an emphasis on private citizens.

The key contribution of this collection is the provision of extensive, detailed comparative assessments of the relative ecological footprint associated with different dimensions of our resource consumption, providing at times surprising insights into the comparative impact of, for example, automobile versus air travel, or the ecological footprint reduction that could be achieved with a lowering of meat consumption. Nearly all chapters highlight the particular challenges of achieving sustainability in a primarily urbanized world. The volume begins with a set of chapters that discuss in general terms the ecological footprint of many dimensions of personal consumption, including food, travel, consumer goods, dwellings, and tourism. This is followed by a smaller collection of chapters representing various dimensions of our "collective footprint," including infrastructure, government, and services; these chapters I found to be among the book's more insightful, as they point to the institutional constraints we face in our efforts at sustainability transition. Rather than synthesizing the current empirical research record on these sectors, however, these chapters tend to frame their arguments around hypothetical scenarios, such as the potential command-and-control governance to achieve sustainability goals compared to a community-based governance system, in the chapter on government, or the waste reduction strategies that would enable a university to reduce its waste stream by 90 per cent, in the chapter on services.

The largest section of the volume provides a collection of in-depth case studies of current consumption in a variety of regions (one chapter offers a useful comparative account of historical and contemporary consumption in Wellington). Regions covered range from New Zealand, England, and Canada to China, Vietnam, and Indonesia. The collection illustrates the vast differences in average individual-level ecological impact, and the means by which those differences are associated with differences in lifestyles and income levels. Some chapters are indeed quite data-heavy, and thus will be of use to other scholars seeking methodological tools and comparative empirical findings for future research, while others might be put off by the large number of data tables and equations. Later in the book, readers will find a handful of chapters that focus on various elements considered to play key roles in transition, including infrastructure, income, and urban form. The concluding chapter is rather short, but offers what I would consider to be one of the most important messages of the book: as the global population has grown, our opportunity windows for sustaining a high quality of life equitably and sustainably 
are closing, since higher populations, simply put, translate into lower per capita fair shares of the services and resources provided by our global ecosystems.

The attention accorded by the Vales and their colleagues to the biophysical dimensions of nature-society relations, making systematic use of a common methodological template-ecological footprint analysis—offers a critical piece of knowledge to contribute to sustainability discussion and planning. The analyses themselves offer quantitative accounts of our current ecological impact and calculate the scale of reduction in impact needed to achieve an ecological footprint that could be absorbed by the carrying capacities of our global ecosystems. I would have appreciated a discussion of the merits and weaknesses of Ecological Footprint analysis, as it certainly is not without its critics, but nonetheless, it has proven extraordinarily useful, as is illustrated particularly with a collection of regional empirical studies such as this book provides.

More importantly, throughout the volume there is a notable gap in consideration for, or even in some chapters in acknowledgement of, the multiple social, cultural, political, and economic dimensions that factor into individual behaviours, and hence behavioural change. While most contributors note the challenge of incentivizing low impact lifestyles, and some chapters pay a bit of attention (albeit insufficient) to the extensive social-scientific field of consumption studies, the book is replete with should statements: what citizens, travelers, city council members, and educators should do to facilitate a sustainability transition, with minimal consideration for why we are not doing so already, despite decades of information availability and encouragement in public discourses. In short, we are provided with findings such as, if the entire green space in suburban Auckland were to be committed to food production by residents, it would supply their annual fruit and vegetable consumption needs. Such calculations are useful, to be sure; however, without their incorporation into the context of social feasibility they are woefully limited in their ability to guide sustainability planning. In this case, the prospects for 100 per cent of upper-middle-class, fully employed Auckland residents to have the knowledge, time, and cultural propensity to voluntarily commit to such land use is slim indeed.

Coinciding with this is an implicit attribution of responsibility for our ecological predicament to private citizens themselves. And yet it is industry, back-stopped by revenue-hungry states, rather than private citizens, which has driven our historical treadmill of production to date, and currently consumes the lion's share of the global ecological commons. To presume that industry's ecological footprint is simply a reflection of companies acting at the behest of consumer demand really glosses over the true nature of market economies; all too often the direction of influence is reversed, with market and state actors driving consumer demand. By the same token, the scale of behavioural change among even environmentally conscious individuals is highly constrained by a complex social system of infrastructures, technologies, markets, and socio-cultural pressures that render personal behaviour far more complex than is depicted by most of the chapters here. 